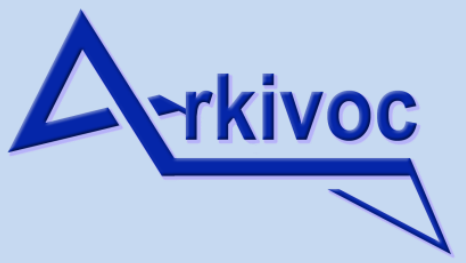

Free to Authors and Readers
A Platinum Open Access Journal for Organic Chemistry
Paper

Arkivoc 2022, part iii, 14-26

\title{
Synthesis of optically active vicinal fluorocyclopentanols and fluorocyclopentanamines by enzymatic deracemization
}

\author{
Olga O. Kolodiazhna, Dmitry V. Prysiazhnuk, Anastasy O. Kolodiazhna, and Oleg I. Kolodiazhnyi* \\ V.P.Kukhar Institute of Bioorganic Chemistry and Petrochemistry, National Academy of Sciences of Ukraine, \\ Murmanska Str., 1, Kiev, Ukraine \\ Email: olegkol321@gmail.com
}

to Professor Gyorgy Keglevich on the occasion of his 65th birthday

Received 09-07-2021

Accepted Manuscript $10-28-2021$

Published on line 11-24-2021

\section{Abstract}

All possible stereoisomers of cis- and trans-2-fluorocyclopentan-1-ols were obtained by kinetically controlled deracemization in the presence of lipases in organic media. High enantioselectivities and good yields of stereomers were obtained for all substrates. Optically pure 1,2-fluorocyclopentan-1-ols were converted to 2fluoro-cyclopentan-1-amines using the Mitsunobu reaction. The absolute configurations were determined using the Kazlauskas rule and chemical correlation. The interaction of substrates with enzymes has considered using Koshland induced fit theory.
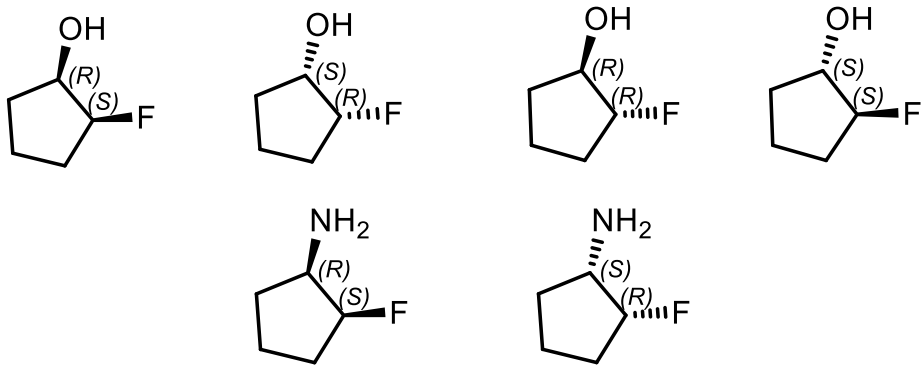

Keywords: Chiral 2-fluorocyclopentan-1-ols, 2-fluorocyclopentan-1-amines, enzymatic deracemisation, Mitsunobu reaction, Koshland induced fit theory 


\section{Introduction}

The synthesis of fluorinated biologically active compounds of high enantiomeric purity (ee> 95\%) has attracted much attention in recent years due to fluorine's ability to increase drugs' lipophilicity, selectivity and duration of action. ${ }^{1}$ However, few methods are known for the synthesis of fluorine-containing compounds of high optical purity. For example, asymmetric metal complex catalysis only in some cases allows the achievement a high level of stereoselectivity in the preparation of chiral organofluorine compounds. Biocatalysis gives the best results. Optically active organofluorine compounds were obtained by such methods as yeast reduction of fluorinated ketones, hydrogenation of activated olefinic double bonds, and deracemization or desymmetrization of fluorinated compounds. ${ }^{2-5}$

Vicinal halocyclopentanols are synthetic blocks for a number of chiral natural and synthetic products. These compounds are used to prepare various biologically active compounds, in particular, prostaglandins and precursors of leukotrienes. ${ }^{6-10}$

We have previously synthesized all possible stereoisomers of cis-halocyclohexanols ( $\mathrm{HIg}=\mathrm{I}, \mathrm{Br}, \mathrm{Cl}, \mathrm{F}$ ) using the kinetic enzymatic resolution of corresponding racemates (Scheme 1). Haufe et al. ${ }^{3}$ and Hashimoto et al. ${ }^{4}$ described the enzymatic deracemization of trans-2-fluorocyclohexane-1-ols, 2-fluorocycloheptan-1-ols, and 2fluorocyclooctan-1-ols using Pseudomonas Fluorescence lipase.

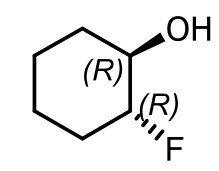

$(-)-(1 R, 2 R)-\mathrm{I}$

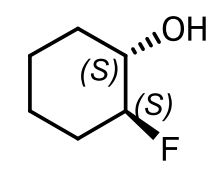

$(+)-(1 S, 2 S)-\mathrm{II}$

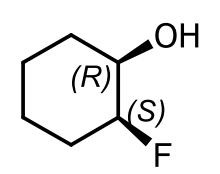

$(+)-(1 R, 2 S)-$ III

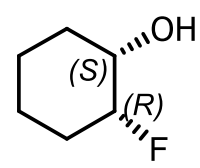

$(-)-(1 S, 2 R)-\mathrm{IV}$

Scheme 1. Chiral 2-fluorocyclohexan-1-ols.

In connection with our studies of the influence of stereochemistry and fluorine atoms on the biological activity of compounds, we have synthesized all four optically pure cis- and trans-stereoisomers of 2fluorocyclopentan-1-ols. These compounds are in demand as synthetic blocks for the preparation of many important biologically active products. For example, 2-substituted cyclopentanols can be converted into conformationally limited leukotriene antagonists, which can then be used in the enantioselective synthesis of (+)-Estron, Estriol, Desogestrel, Eicosanoids (V-VIII), and others (Scheme 2). ${ }^{1}$

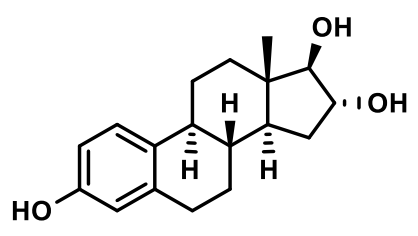

V

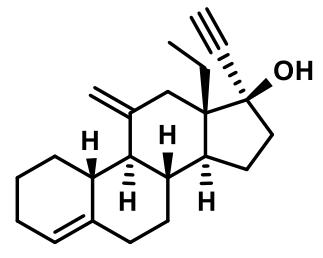

VI

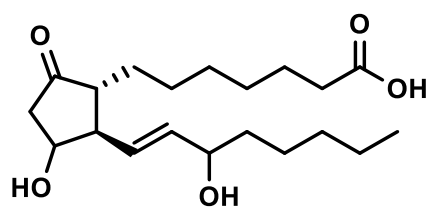

VII

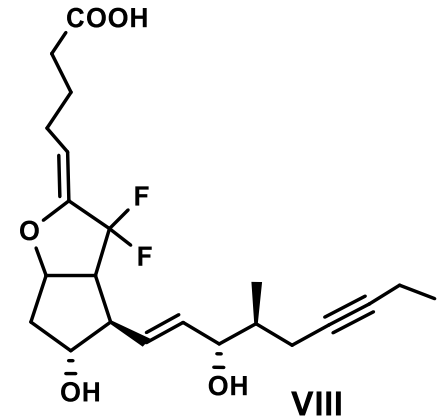

VIII

Scheme 2. Natural compounds containing a cyclopentane ring. 


\section{Results and Discussion}

Stereoisomers of 2-fluorocyclopentan-1-ols are rarely studied compounds. Chiral stereoisomers of 2fluorocyclopentan-1-ols $(1 S, 2 R)-\mathbf{1},(1 R, 2 S)-\mathbf{2}$, and $(1 R, 2 R)-\mathbf{4}$ have not been previously described and their stereochemical properties have not been studied. Only 2-fluorocyclopentan-1-ol (1S,2S)-3 was obtained by Kalow and Doyle ${ }^{2,11}$ with moderate stereoselectivity by asymmetric cleavage of mesomeric cyclopentene oxide with fluorine anions in the presence of chiral salen(Co) complexes. In this work, we report on an enzymatic approach to the preparation of enantiomerically pure stereoisomers of 2-fluorocyclopentan-1-ols (Scheme 3).

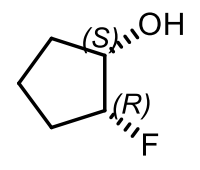

$(-)-(1 S, 2 R)-1$

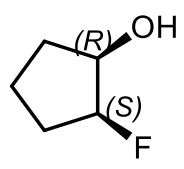

$(+)-(1 R, 2 S)-2$

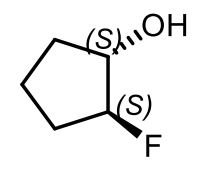

$(+)-(1 S, 2 S)-3$

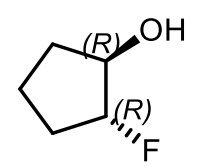

$(-)-(1 R, 2 R)-4$

Scheme 3. Chiral 2-fluorocyclopentan-1-ols.

Racemic trans-2-fluorocyclopentan-1-ol (+/-)-6 was synthesized from epoxides by opening the threemembered ring with hydrofluorinating agents (Scheme 4). Reactions with pure HF or HF in combination with bases such as tetrahydrofuran or pyridine are sometimes accompanied by rearrangements; however, such competing processes were not observed with less acidic but more nucleophilic reagents such as trimethylamine trishydrofluoride ( $\mathrm{Et}_{3} \mathrm{~N} .3 \mathrm{HF}$ ) or pyridinium poly(hydrogenfluoride) $(\mathrm{C} 5 \mathrm{H} 5 \mathrm{~N} \bullet 9 \mathrm{HF}) .{ }^{3}$ For the preparation of the desired fluorohydrins we have treated epoxide 5 with $\mathrm{C}_{5} \mathrm{H}_{5} \mathrm{~N} \bullet 9 \mathrm{HF}$. As a result, the racemic trans-2fluorocyclopentanols (+/-)-6 were obtained. Unlike racemates of trans-fluorocyclopentan-1-ol (+/-)-6, racemic cis-fluorocyclopentan-1-ol (+/-)-8 was obtained with an admixture of the trans-isomer. To obtain pure cis-2fluorocyclopentan-1-ols, we used the preparative method developed earlier by us (Scheme 4). ${ }^{12}$

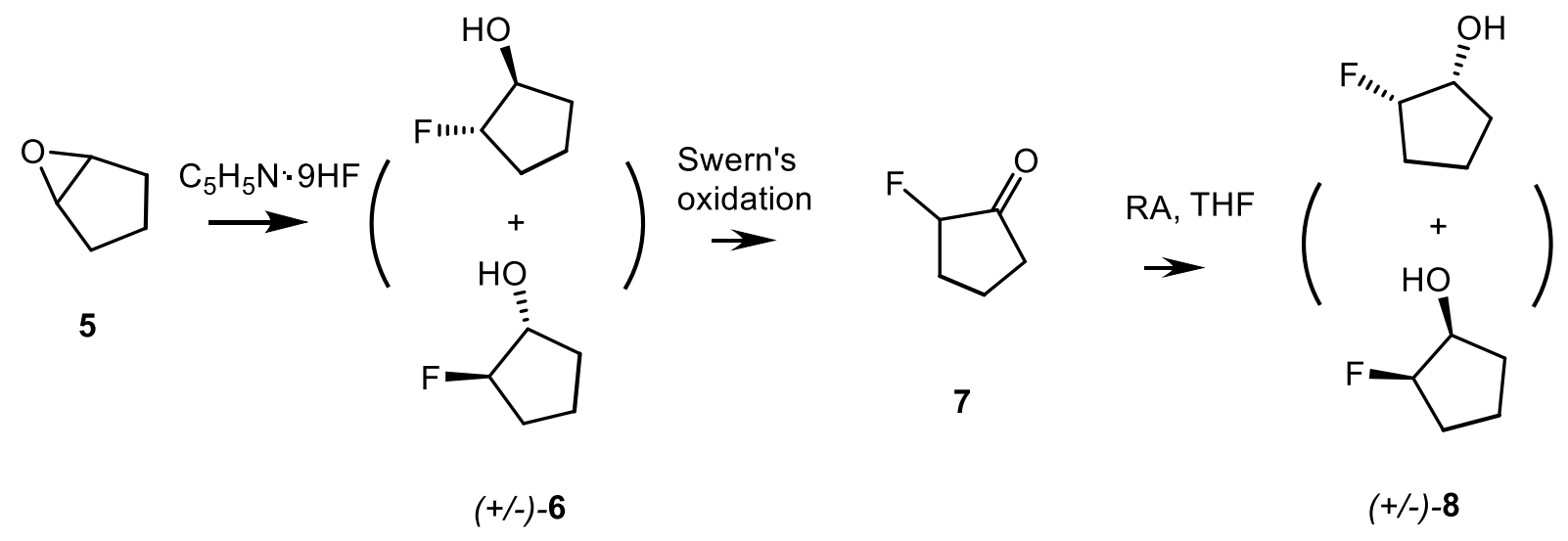

$\mathrm{RA}=\left[\mathrm{i}-\mathrm{Bu}_{3} \mathrm{BH}\right] \mathrm{K}, \mathrm{i}-\mathrm{Bu}_{2} \mathrm{AlH}, \mathrm{NaBH}_{4} / \mathrm{MeOH}$

Scheme 4. Synthesis of racemic cis- and trans-2-fluorocyclopentan-1-ols.

For this purpose, racemic trans-2-fluoro-substituted cyclopentanol (+/-)-6 was underwent to Swern oxidation with the formation of 2-fluorocyclopentanone $\mathbf{7}$ in good yields. Ketone $\mathbf{7}$ was reduced with various reducing reagents, that led to the formation of cis-2-fluorocyclopentan-1-ol with an admixture of trans-isomers. 
The best results were obtained with $\mathrm{K}$-Selectride $\left[\left(\mathrm{i}-\mathrm{Bu} \mathrm{u}_{3} \mathrm{BH}\right) \mathrm{K}\right]$, which gave a mixture of cis- and trans-isomers in a ratio of 75:25, reduction with sodium borohydride in methanol gave a ratio of $70: 30$, and the reduction with $\mathrm{i}-\mathrm{Bu}_{2} \mathrm{AlH}$ (H-DIBAL) resulted in a 55:45 ratio. Subsequent treatment of a mixture of cis- and trans-2fluorocyclopentanols with base (DBU and others) proceeded with the preferential hydrolysis of the transisomer, that leads to the enrichment of mixture with the unreacted cis-isomer (Table 1). As a result, after additional low-temperature recrystallization in pentane or hexane, a pure cis isomer can be obtained. (Table 1). The reductions of 2-substituted fluoropentanones depended on the conformational equilibrium of the axial and equatorial forms: equatorial attack of the nucleophile leads to the formation of trans-alcohols while the axial attack provides the cis-alcohols. The cis-isomers of 2-halogencycloalkan-1-ols are more stable toward basemediated HX-elimination than the trans-isomers. Unlike trans-isomers (+/-)-6, which upon alkali treatment easily convert into epoxide 5, cis-isomers (+/-)-8 with excess DBU converted into cyclopentanone. The cis orientation of the oxygen and halogen atoms is unavailable for intramolecular $\mathrm{S}_{\mathrm{N}} 2$ reaction with the formation of the epoxide, because nucleophile cannot attack the stereocentre from the front side. In this case, an alternative anti-conformation B (via ring flip) is available for rearrangement via hydride migration and the cyclohexanone formation (Scheme 5). ${ }^{12}$
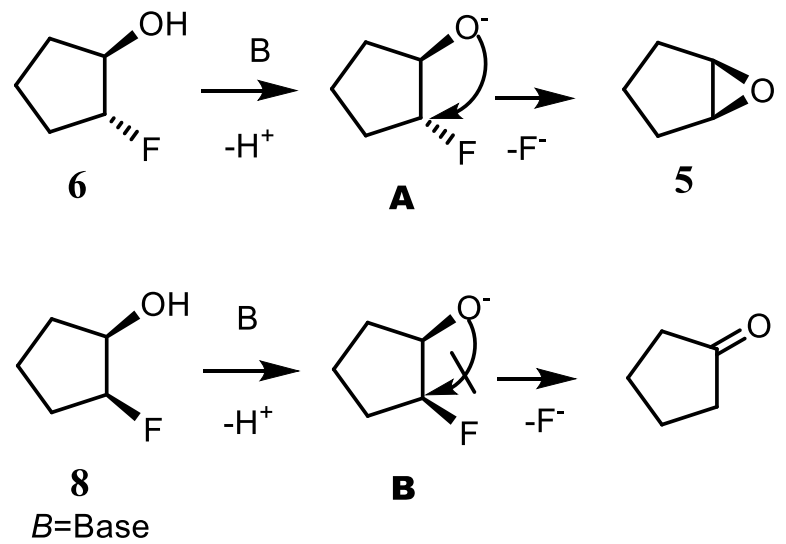

Scheme 5. Base-mediated reaction of cis- and trans-fluorocyclopentan-1-ols.

Table 1. Preparation of racemic cis-2-fluorocyclopentanols (+/-)-8

\begin{tabular}{clccc}
\hline Compound & Reductant/solvent & Yields (\%) $^{\text {a) }}$ & Yields (\%) $^{\text {b) }}$ & cis/trans \\
\hline 7 & $\mathrm{NaBH}_{4} / \mathrm{MeOH}$ & 70 & 38 & $70: 30$ \\
7 & {$\left[\mathrm{i}-\mathrm{Bu}_{3} \mathrm{BH}\right] \mathrm{K} / \mathrm{THF}$} & 50 & 33 & $75: 25$ \\
7 & $\mathrm{i}-\mathrm{Bu}_{2} \mathrm{AlH} /$ toluene & 50 & - & $55: 45$ \\
\hline
\end{tabular}

a Yields for the mixture of the cis- and trans-isomers.

${ }^{b}$ Yields for the purified cis-isomer (+/-)-8.

To deracemize 2-fluorocyclopentanols and obtain enantiomerically pure compounds, we used several lipases with well-known biocatalytic activity in organic solvents using vinyl acetate or isopropenylidene acetate as an acylating reagent. We tested Candida antarctica (CAL-B), Pseudomonas cepacia (PCL) and Burkholderia cepacia $(\mathrm{BCL})$. The best results (highest ee) were obtained with $\mathrm{BCL}$; therefore, this lipase was used. Enzymatic esterification in the presence of $\mathrm{BCL}$ immobilized on diatomaceous earth allowed separation of the racemic 
fluorocyclopentanols into enantiomerically pure optically active stereoisomers. The esterification was carried out at room temperature and stopped at $50 \%$ conversion to acetate, which was achieved by filtration of the biocatalyst from the reaction mixture. In all cases, the products were obtained with very good enantiomeric excesses (ee).

The acylation of 2-fluorocyclopentanols (+/-)-6 biocatalyzed by $\mathrm{BCL}$ proceeded with the highest enantioselectivity to provide $(1 R, 2 R)-4$ with $96 \%$ ee (Scheme 6$)$. Acylation in the presence of the CALB biocatalyst proceeded faster, then with $\mathrm{BCL}$, but the enantioselectivity of reaction was lower. In turn, the transesterification of the corresponding fluorocyclopentanols with vinyl acetate proceeded faster than with propenyl acetate. However, the enantioselectivity in this case was also slightly lower. Usually, esterification with vinyl acetate proceeds relatively slowly and within 15-18 hours leads to a 50\% conversion of (+/-)-6 to acetate $(R, R)-\mathbf{9}$.
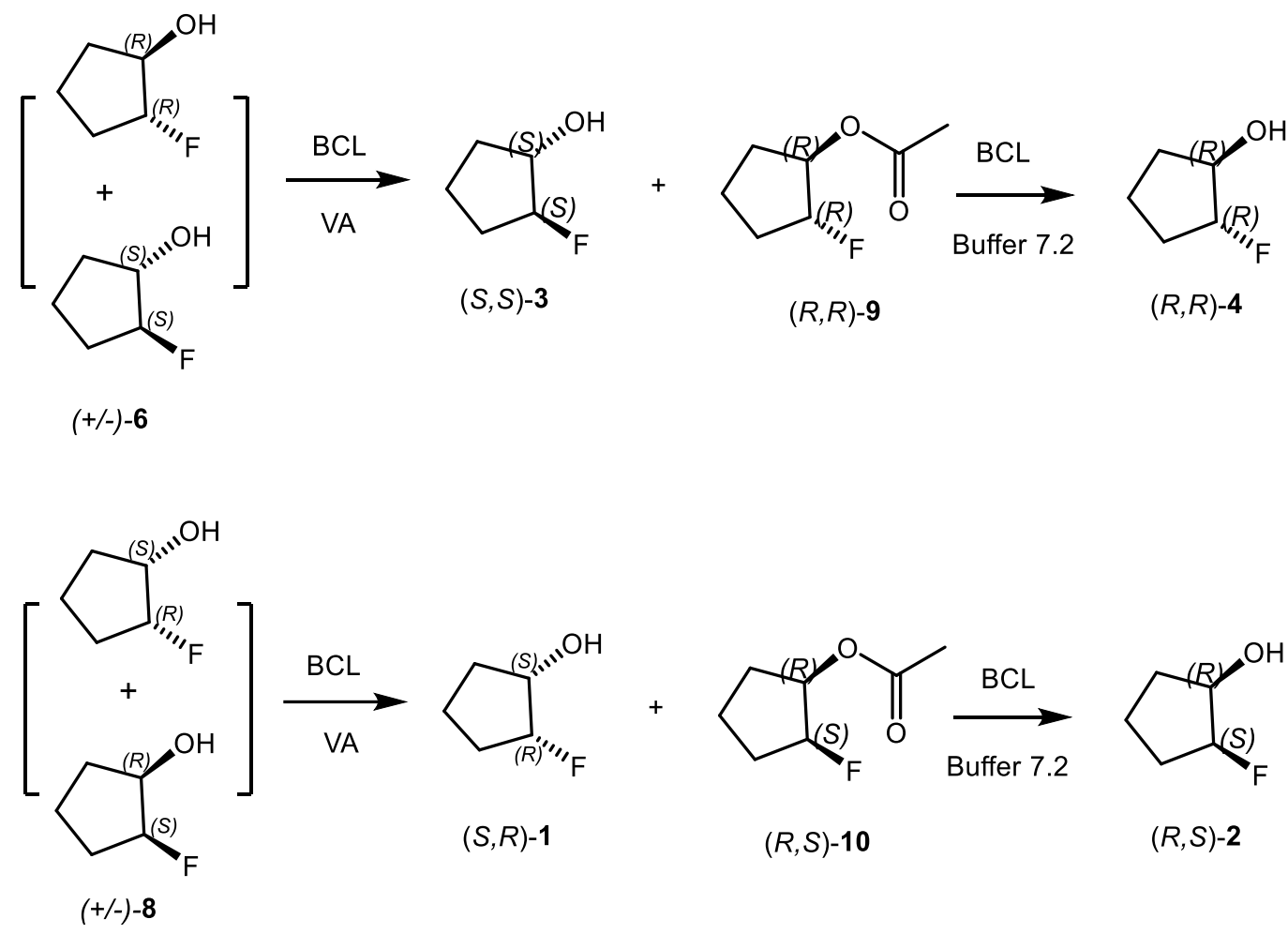

Scheme 6. Enzymatic deracemization of 2-cis- and trans-fluorocyclopentanols 6,8.

The esterification process was monitored by ${ }^{1} \mathrm{H}$ NMR spectroscopy, evaluating the change in the intensity of the $\underline{\mathrm{C}} \mathrm{OAC}(5.3 \mathrm{ppm})$ and $\mathrm{C} \underline{\mathrm{HOH}}(4.4 \mathrm{ppm})$ signals until they reached a 50:50 ratio. The enantiomeric purity of the products of enzymatic resolution was determined by derivatization of alcohols 1,2 with (S)- $\alpha$-methoxy- $\alpha$ trifluoromethylphenylacetic acid chloride [(S)-MTPA-Cl] proceeding with the formation of Mosher esters in accordance with the established protocol. Mosher esters were analyzed by ${ }^{19} \mathrm{~F}$ NMR spectroscopy of each isolated stereoisomer of 2-fluorocyclopentan-1-ols. In the case of cis-2-fluorocyclopentan-1-ols, after separation by column chromatography, the optically active alcohols $(+)-(1 S, 2 R)-7$ and acetates $(-)-(1 R, 2 S)-9$ were obtained with an enantiomeric excess (ee) of 96-98\% and enantioselectivity $>100$.

Similarly, acylation of racemic trans-cyclopentanol with vinyl acetate in the presence of BCL under kinetically controlled conditions (50\% conversion of the starting alcohol) led to the formation of alcohols $(1 R, 2 S)-\mathbf{2}$ and acetates $(1 R, 2 R)-\mathbf{9}$ that were isolated by column chromatography. Hydrolysis of $(1 R, 2 R)-\mathbf{9}$ acetates in phosphate 
buffer at $\mathrm{pH} 7.2$ gave the second stereoisomer of $(1 R, 2 R)$-fluorocyclopentanol with high enantiomeric and diastereomeric purity.

Hydrolysis of the obtained acetates $\mathbf{9 , 1 0}$ with BCL lipase in phosphate buffer at pH 7.2 led to the formation of the second stereoisomer of alcohols 2, 4 with high enantiomeric purity (98-99\% ee). Acetates 9, 10 were also hydrolyzed with $\mathrm{K}_{2} \mathrm{CO}_{3}$ in methanol to afford the hydrolyzed alcohols 2, 4 with the same ee and yields (Table 2). Additional low-temperature $\left(-20{ }^{\circ} \mathrm{C}\right)$ crystallization of alcohols in pentane made it possible to obtain enantiomerically pure alcohols $(1 R, 2 S)-2$ and $(1 R, 2 R)-4$ with de and ee $>97-98 \%$, that was determined by derivatization of the compounds with Mosher's acid. Enantiomerically pure 2-fluorocyclopentan-2-ols are colorless low-melting compounds or liquids that are stable at room temperature or in a refrigerator. No racemization was observed during operation with 2-fluorocyclopentan-1-ols or during storage.

Table 2. Enzymatic resolution of 2-fluorocyclopentan-1-ols 1-4 by Burkholderia cepacia lipase-catalyzed esterification using vinyl acetate as acyl donor

\begin{tabular}{|c|c|c|c|c|c|c|c|}
\hline Entry & $\begin{array}{l}\text { Conversion } \\
(\%)^{c}\end{array}$ & $\tau(h)$ & Yield (\%) & $\begin{array}{l}e e^{b, c} \\
(\%)\end{array}$ & {$[\alpha]_{D}^{20}(E t O H)^{d}$} & Configuration & $\mathrm{E}^{\mathrm{a}}$ \\
\hline \multicolumn{8}{|c|}{ Unreacted alcohol } \\
\hline 1 & 50 & 16 & 45 & 99 & -20 & $(1 S, 2 R)-1$ & $>100$ \\
\hline 2 & 50 & 17 & 40 & 97 & +25 & $(1 S, 2 S)-3$ & $>100$ \\
\hline \multicolumn{8}{|c|}{ Recovered alcohol } \\
\hline 3 & 50 & 16 & 40 & 99 & +18 & $(1 R, 2 S)-2$ & $>100$ \\
\hline 4 & 50 & 17 & 40 & 98 & -20 & $(1 R, 2 R)-4$ & $>100$ \\
\hline
\end{tabular}

${ }^{a}$ Calculated by the acylated conversion and\% ee of the product. $E=\ln \left[1 c\left(1+e e_{p}\right)\right] / \ln \left[(1 c)\left(1 e e_{p}\right)\right]$, where $p=$ product.

${ }^{b}$ Determined from the ${ }^{19} \mathrm{~F}$ NMR spectra of the respective MTPA esters.

c Obtained from the NMR spectra of the MTPA esters of the recovered alcohols.

$d[\alpha]_{D}$ and ee were defined for isolated and purified products.

The nature of the solvents used had no significant effect on the enantioselectivity of the kinetic resolution. However, diisopropyl ether (DIPE) and methyl-tert-butyl ether (MTBE) or solvent-free vinyl acetate showed the highest $e e$, while the reaction proceeded faster in cyclohexane. In the case of trans-2-fluorocyclopentanol (+/-) -6 , the reaction in the above-mentioned solvents took much longer and the enantioselectivity was slightly lower. The rate of acylation of 2-fluorocyclopentanols with vinyl acetate and PCL in DIPE was slightly higher compared to the corresponding reactions with isopropenylidene acetate. In all cases, $(R)$-selectivity was observed in accordance with the Kazlauskas' rule. Better solubility of most substrates in organic solvents and easy separation of immobilized lipases promote reactions in organic media. In accordance with the theory of Koshland ("induced fit model"), it is implied the flexibility of the active site of the deracemization reaction. The attachment of the substrate to the active center of the enzyme causes a change in the configuration of the catalytic center, as a result of which its shape matches the shape of the substrate ("hand-glove"). If this transformation contributes to better complementarity of the substrate and the active center, then this gives a gain in the reaction rate, i.e. provides a significant catalytic effect. Due to their mutual influence, when the substrate approaches the active 
center of the enzyme, the structures of both reacting molecules are transformed. Thus, the polar interactions of different parts of the protein become stronger, and the enzyme becomes more rigid in conformational terms (Scheme 7). ${ }^{13-15}$
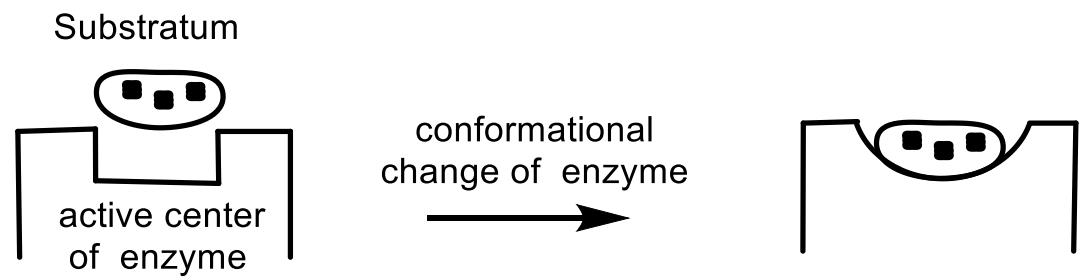

Scheme 7. Conformational change in the active centre of enzyme according to the "induced fit model".

The structure and purity of the reaction products were confirmed by physical-chemical methods. The ${ }^{13} \mathrm{C}$ NMR spectra of 2-fluorocyclopentanols show signals from all five carbon atoms split at the fluorine atom [ ${ }^{1} J_{\mathrm{CF}}$ $177 \mathrm{~Hz}(\mathrm{C}-\mathrm{F})$ ]. In the proton resonance spectra, there are doublets of the signals of $\mathrm{CHF}$ and $\mathrm{CHOH}$ groups at 4.3 and $4.8 \mathrm{ppm}$, respectively. The signal of the fluorine atom was discovered at $-185 \mathrm{ppm}$. The mass spectra contain signals of mass peaks. The purity of the compounds was confirmed by HPLC using a chiral column "Chiralcel OJ$\mathrm{H}^{\prime \prime}$.

To confirm the structures and absolute configuration of 2-fluorocyclopropanols, we converted the $(1 S, 2 S)$ and $(1 R, 2 R)$-2-fluorocyclopentanols into enantiomers of $(1 R, 2 S)$ - and (1S,2R)-2-fluoro-1aminocyclopentanols ${ }^{16,17}$ using the Mitsunobu reaction. A solution of alcohol in THF was reacted with phthalimide in the presence of triphenylphosphine and diethyl azodicarboxylate (DEAD). The reaction proceeded with the inversion of the absolute configuration at the carbon atom containing the hydroxyl group. After the reaction was completed, the products were isolated by column chromatography $\mathbf{1 2 , 1 4}$. The products were then treated with hydrochloric acid to form aminofluorocyclopentane hydrochloride. As a result, trans1,2-fluorocyclopentanol was converted to cis-1,2-aminofluorocyclopentanes. Pure products were obtained with an enantiomeric excess of $95 \%$ ee (Scheme 8). 2-Fluorocyclopentyl-1-amines are of interest as intermediates for the synthesis of a number of important biologically active compounds: For example, they can be used in the synthesis of potent and selective opioid receptor-like antagonists. ${ }^{15,16}$

The resulting products $\mathbf{1 2 , 1 4}$ were separated by column chromatography. The yields of diones $\mathbf{1 1 , 1 3}$ and amines $\mathbf{1 2 , 1 4}$ were 70 and $90 \%$ correspondingly (Scheme 8). 


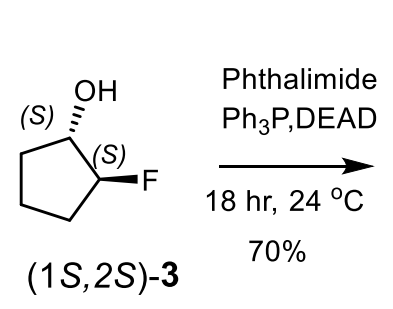

Exact Mass: 233,09 Molecular Weight: 233,24

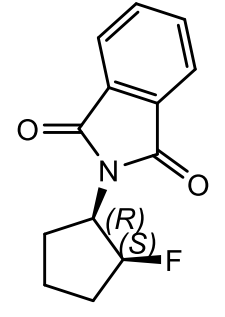

11

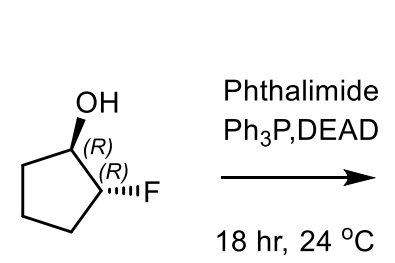

$(1 R, 2 R)-4$

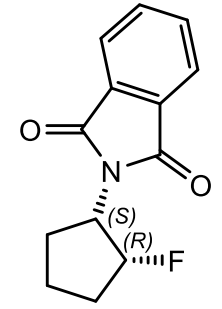

13

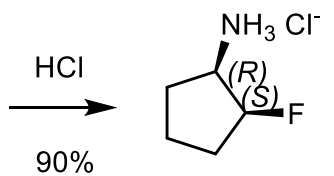

$(1 R, 2 S)-12$
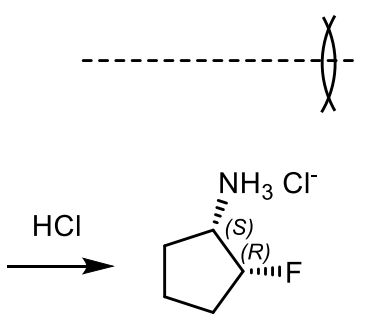

$(1 S, 2 R)-14$

Scheme 8. Synthesis of chiral 2-fluorocyclopentan-1-amine hydrochloride using Mitsunobu reaction.

The optical purities of the $(R, S)$ - and $(S, R)$-2-fluorocyclopentan-1-amines 12, 14 were on the order of $96 \%$ determined by derivatization with Mosher's acid. The structures of amines were confirmed by NMR and massspectra. In the NMR spectra of the hydrochlorides the signals of $\mathrm{NH}_{3}{ }^{+}$protons at $8.5 \mathrm{ppm}$, signals of $\mathrm{C} \underline{\mathrm{HF}}$ at 5.1 ppm, a doublet with ${ }^{2} J_{\mathrm{HF}}$ constant $55 \mathrm{~Hz}$ and $\mathrm{CHN}$ at $3.4 \mathrm{ppm}$, doublet, ${ }^{2} J_{\mathrm{HF}} 26 \mathrm{~Hz}$, as well as the $\mathrm{CH}_{2}$ protons were observed. ${ }^{17}$

The definition of absolute configuration. Kazlauskas rule ${ }^{18}$ was used for determination of the absolute stereochemistry of the resolved 2-fluorocyclopentanols. According to the Kazlauskas rule, the enantioselectivity should be proportional to the size difference between the large (L) and medium-size (M) substituents in the substrate. The physical essence of the Kazlauskas rule is determined by structure of lipase active center, which has two pockets - one is larger and the other is smaller. In accordance with the structure of the active center, the orientation of the secondary alcohol occurs and the esterification/hydrolysis of the corresponding esters proceeds. According to the Kazlauskas rule, the biocatalytic acetylation of 2-fluorocyclopentan-1-ols should be $(R)$-selective, leading to the formation of $(1 R, 2 S)$-acetates and $(1 S, 2 R)$-unreacted alcohols in the case of the cisfluorocyclopentanols and correspondingly to the formation of $(1 R, 2 R)$-acetates and $(1 S, 2 S)$-unreacted alcohols in case of trans-2-fluorocyclopentanols (Scheme 9). ${ }^{19}$ Empirically, as shown earlier on a very large number of examples, trans-esterification of secondary alcohols in the presence of $\mathrm{BCL}$, and as well as of many other lipases, always leads to the formation of $(R)$-acetate and unreacted $(S)$-alcohol. Therefore we have obtained the cis$(1 R, 2 S)-10$ acetate and the cis-(1S,2R)-3 alcohol, as well as trans-(1R,2R)-9 acetate and trans-(1S,2S)-2 alcohol. Enzymatic kinetic resolution is a fairly reliable method for the determining of absolute configuration. ${ }^{20-22}$ In addition, we confirmed the results obtained on the basis of the Kazlauskas rule by independent synthesis of (1S, 2S) -fluorophosphonate $\mathbf{2}$ whose configuration is known. ${ }^{2}$ The determination of absolute configuration of compound 2, attained by two different methods was identical. 

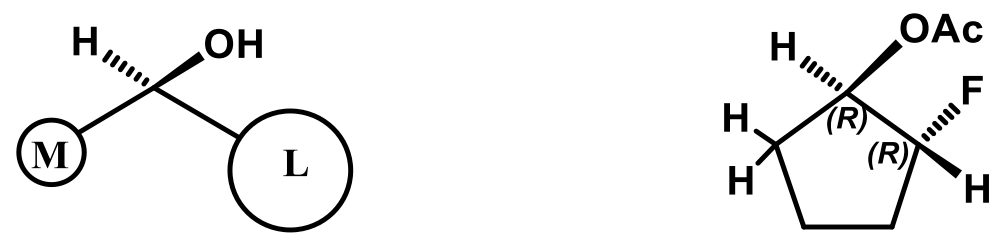

Scheme 9. Enzymatic transesterification of 2-fluorocyclopentan-1-ols according to the Kazlauskas rule.

\section{Conclusions}

Enantiomerically pure $(1 R, 2 S)-, \quad(1 S, 2 R)-,(1 S, 2 S)$ - and $(1 R, 2 R)-2$-fluorocyclopentanols were obtained by biocatalytic kinetic resolution in good yields and with high enantiomeric excesses. Burkholderia cepacia lipase has shown excellent enantioselectivity as a biocatalyst for the transesterification of 2-fluorocyclopentan-1-ols with vinyl acetate. The trans-2-fluorocyclopentan-1-ols were converted into $(1 R, 2 S)$ - and $(1 S, 2 R)$-cis-2fluorocyclopentane-1-amines using the Mitsunobu reaction. The absolute configuration of enantiomerically pure 2-fluorocyclopentan-1-ols was determined in accordance with Kazlauskas rule. In contrast to the multistage and difficult to access asymmetric metal complex synthesis of chiral 2-fluorocyclopentan-1-ols, the present methodology is simple and uses commercially available lipases.

\section{Experimental Section}

General. ${ }^{1} \mathrm{H}(500 \mathrm{MHz})$ and ${ }^{13} \mathrm{C}(125 \mathrm{MHz})$ NMR spectra were recorded on Bruker Avance DRX 500 spectrometer in dimethylsulfoxide (DMSO- $d_{6}$ ) solution with tetramethylsilane (TMS) as an internal standard. Unless otherwise specified NMR spectra have been made in $\mathrm{CDCl}_{3}$ Chemical shifts $(\delta)$ of ${ }^{1} \mathrm{H}$ and ${ }^{13} \mathrm{C}$ are reported in ppm relative to $\mathrm{CHCl}_{3}\left(\delta=7.26\right.$ for ${ }^{1} \mathrm{H}$ and $\delta=77.0$ for $\left.{ }^{13} \mathrm{C}\right)$. J values are given in $\mathrm{Hz}$. Proton $\left({ }^{1} \mathrm{H}\right) \mathrm{NMR}$ information is given in the following format: multiplicity ( $s$, singlet; $d$, doublet; $t$, triplet; $q$, quartet; sept; septet; m, multiplet, b, broad), coupling constant J, number of protons). Melting points were measured with a Büchi melting-point apparatus and are uncorrected. The chromatomass spectra were recorded on an Agilent 1100 Series high-performance liquid chromatograph equipped with a diode matrix with an Agilent LCnMSD SL mass selective detector, allowing fast switching of the ionization modes. The GC-MS studies were performed using an Agilent Technologies 1200 device. The HPLC was performed with Chiralcel OJ-H chiral column $(250 * 4,6 \mathrm{~mm}, 5 \mathrm{mkm}$ with Selector Celulose tris(4-methylbenzoate) coated on $5 \mathrm{~m} \mu$ silica gel. The reaction progress was monitored by thin-layer chromatography (TLC) on silica gel $6 \mathrm{~F}_{254}$ Merck and visualized under ultraviolet light (254 and $366 \mathrm{~nm}$ ), or through spraying with $5 \%$ phosphomolybdic acid in $\mathrm{EtOH}, \mathrm{H}_{2} \mathrm{SO}_{4}$ acidified by Anise aldehyde solution in EtOH or by placing in iodine vapor. Flash chromatography was performed with Merck silica gel 60 (230-400 mesh). Most part of the reactants were obtained from a commercially available source (Aldrich) and used without further purification. All solvents were purified by standard procedures or obtained from a Solvent Purification System (Braun SPS 800). Unless otherwise mentioned, all reactions were carried out under an atmosphere of dry argon.

trans-2-fluorocyclopentan-1-ol, [(+/-)-6]. To $6.00 \mathrm{~mL}$ (5.78 g, 0.069 moles) of cyclopenten oxide in $70 \mathrm{~mL}$ of 1.0 $\mathrm{M}$ triethylamine trihydrofluoride was added $20 \mathrm{~mL}$ of poly(hydrogen fluoride) pyridinium slowly via the polypropylene syringe at $0{ }^{\circ} \mathrm{C}$ at magnetic stirring. The mixture was left warmed to room temperature and then 
stirred for 3 hours. The consecutive treatment with water and diethyl ether extraction. washing with aqueous sodium hydrogen carbonate drying with anhydrous magnesium sulfate and concentrating on a rotary evaporator gave an oil which was purified by distillation in vacuo. Yield $3.65 \mathrm{~g}(50 \%)$, bp $55-57^{\circ} \mathrm{C}(20 \mathrm{mmHg})$. Lit. bp. $35-38{ }^{\circ} \mathrm{C}(15 \mathrm{mmHg}) \cdot{ }^{24}$ bp. $55-57{ }^{\circ} \mathrm{C}(18 \mathrm{mmHg}) .{ }^{25,26}$

${ }^{1} \mathrm{H} \operatorname{NMR}\left(\delta, \operatorname{ppm}(J, \mathrm{~Hz}), \mathrm{CDC1} 1_{3}\right): \delta_{\mathrm{H}} 1.3-2.00\left(\mathrm{~m}, 6 \mathrm{H}, \mathrm{CH}_{2}\right) ; 2.0-2.1$ (br.m, $\left.1 \mathrm{H}, \mathrm{OH}\right) ; 4.30(\mathrm{~d}, J 14,1 \mathrm{H}, \mathrm{C} \underline{\mathrm{HOH}}) ; 4.90$ (ddt, J 52.0, J 8.4 and J 2.8, 1H, CㅂF). ${ }^{13} \mathrm{C} \mathrm{NMR} \mathrm{(75.4} \mathrm{MHz,} \mathrm{CDCl}_{3}$ ); $\delta \mathrm{c:} 19.7$ (d, J 1.7); 29.0 (d, J 21.54); 31.2 (d, J 1.7); $77.0(\mathrm{~d}, J 27.2) ; 98.9(\mathrm{~d}, J 177)$. NMR ${ }^{19} \mathrm{~F}, \delta_{\mathrm{F}}-185 \mathrm{ppm}$. Spectral data were in agreement with literature reported values. ${ }^{24}$

cis-2-Fluorocyclopentan-1-ol, [(+/-)-8]. a) 2-Fluorocyclopentan-1-one 7. $3.6 \mathrm{~mL}$ (50 mmol) of DMSO in $10 \mathrm{~mL}$ of methylene chloride at $-70^{\circ} \mathrm{C}$ was added dropwise to a solution of oxalyl chloride ( $2.9 \mathrm{~g}$. $23 \mathrm{mmol}$ ) in $40 \mathrm{~mL}$ of methylene chloride. The trans-2-fluorocyclopentan-1-ol $(2.1 \mathrm{~g}, 20 \mathrm{mmol})$ was added at the same temperature and the reaction mixture was stirred for 20 minutes. The temperature was then raised to $-55^{\circ} \mathrm{C}$ and $16 \mathrm{~mL}$ of triethylamine was added. The reaction mixture was stirred for $20 \mathrm{~min}$., warmed to $0{ }^{\circ} \mathrm{C}$. and poured into a $1 \mathrm{M}$ aqueous solution of hydrochloric acid. The aqueous phase was separated and extracted with methylene chloride. the combined extracts were washed with water, and dried over anhydrous sodium sulfate. The solvent was distilled off under atmospheric pressure with an effective column.

b) Cis-2-Fluorocyclopentanol was prepared from the fluorocyclopentanone 7 (1.1 g, $10 \mathrm{mmol}$ ) in $50 \mathrm{~mL}$ of methanol and sodium borohydride $(3.5,0.1 \mathrm{~mol})$ at $0{ }^{\circ} \mathrm{C}$ according to general methodology earlier described by us. ${ }^{12}$ Yield $50 \%$, bp $55{ }^{\circ} \mathrm{C}(15 \mathrm{~mm} \mathrm{Hg})$. Lit. bp $55-57{ }^{\circ} \mathrm{C}(18 \mathrm{mmHg}) .{ }^{25,26}$

c) Racemic cis-2-fluorocyclopentanol can also be prepared similarly to the method developed by Basso for the reduction of 2-fluorocyclohexanone in anhydrous THF using K-selectride. ${ }^{23}$ The product contains impurity of the trans-isomer as an impurity. Yield $45 \%$, bp $55^{\circ} \mathrm{C} / 14 \mathrm{~mm} \mathrm{Hg}$.

${ }^{1} \mathrm{H}$ NMR $\left(\delta, \operatorname{ppm}(J, \mathrm{~Hz}), \mathrm{CDC1}_{3}\right): \delta 1.25-1.35\left(\mathrm{~m}, 2 \mathrm{H}, \mathrm{CH}_{2}\right) ; 1.5-1.70\left(\mathrm{~m}, 5 \mathrm{H}, \mathrm{CH}_{2} \mathrm{CH}_{2}\right) ; 2.0-2.1$ (br.m, $\left.1 \mathrm{H}, \mathrm{OH}\right) ; 2.4$ (br, $1 \mathrm{H}, \mathrm{OH}) ; 3.78(\mathrm{~d}, 1 \mathrm{H}, J$ 5, CHOH); 4.69 (dd, JHF $40 \mathrm{~Hz} . J 3 \mathrm{~Hz}, 1 \mathrm{H}, \mathrm{CHF}) ;{ }^{13} \mathrm{C} \mathrm{NMR}(\delta, \mathrm{ppm}(J, \mathrm{~Hz}), \mathrm{CDCl} 3): \delta \mathrm{c}$ : 19.7 (d, J 1.7); 29.0 (d, J 21.54); 31.2 (d, J 1.7); 77.0 (d, J 27.2); 98.9 (d, J 177); NMR ${ }^{19} \mathrm{~F}, \delta_{\mathrm{F}}-185$ ppm. Found, \%: C 57.35; $\mathrm{H}$ 8.78. $\mathrm{C}_{5} \mathrm{H}_{9} \mathrm{FO}$. Calculated, \%: C 57.68; $\mathrm{H} 8.71$.

(-)-(1S,2R)-2-Fluorocyclopentane-1-ol, (1). The racemic 2-fluorocyclopentane-1-ol (2,1 g, $20 \mathrm{mmol})$ was dissolved in MTBE and vinyl acetate $(2.5 \mathrm{~mL}, 30 \mathrm{mml}$.) as the acylating agent. Burkholderia cepacia lipase immobilized on diatomite $(0.5 \mathrm{~g})$ was added as a biocatalyst. The reaction mixture was stirred at room temperature for 14-15 hours. The reaction was monitored by NMR. When the reaction passes above $50 \%$ completion, the lipase was filtered off and the solvent evaporated. The residue [a mixture of alcohol 1 (50\%) and acetate 10 (50\%)] was separated by column chromatography using hexane-ethyl acetate (95:5) as eluent. Acetate 10 (yield $\sim 50 \%$ ) was found in the first fraction and in the second fraction, $(1 S, 2 R)$-fluorocyclopentane1-ol $(1 S, 2 R)$-1, yield $\sim 50 \%$ (not purified state). The solvent was evaporated, and a colorless oil was obtained. The product was crystallized in pentane at low temperature. Yield $45 \%,[\alpha]_{D}^{20}=-20\left(\mathrm{C}-1, \mathrm{CHCl}_{3}\right)$. Optical purity was determined by Mosher acid derivatization and HPLC with (Chiralcel OJ-H) chiral column.

${ }^{1} \mathrm{H} \operatorname{NMR}\left(\delta, \operatorname{ppm}(\mathrm{J}, \mathrm{Hz}), \mathrm{CDC1}_{3}\right): \delta 1.25-1.35\left(\mathrm{~m}, 2 \mathrm{H}, \mathrm{CH}_{2}\right) ; 1.5-1.70\left(\mathrm{~m}, 5 \mathrm{H}, \mathrm{CH}_{2} \mathrm{CH}_{2}\right) ; 2.0-2.1\left(\mathrm{~m}, 1 \mathrm{H}, \mathrm{CH}_{2}\right) ; 2.4$ (br.m, $1 \mathrm{H}, \mathrm{OH}$ ); 3.78 (d, 1H, J 5, CㅂO); 4.69 (dd, J JF $40 \mathrm{~Hz}, J 3 \mathrm{~Hz}, 1 \mathrm{H}, \mathrm{CHF}$ ).

${ }^{13} \mathrm{C} N M R\left(\delta, \operatorname{ppm}(J, \mathrm{~Hz}), \mathrm{CDC1} 1_{3}\right): \delta \mathrm{c}: 19.7 ; 27.0(\mathrm{~d}, J 21.54) ; 31.0(\mathrm{~d}, J$ 1.7); 56.0 (d, J 27.2); 94 (d, J 177);

${ }^{19} \mathrm{~F}$ NMR, $\delta_{F}-180.5$ ppm. Found, \%: C 57.35; H 8.78. $\mathrm{C}_{5} \mathrm{H}_{9} \mathrm{FO}$. Calculated, \%: C 57.68; H 8.71.

(+)-(1R,2S)-Fluorocyclopentane-1-ol, (2). (1R,2S)-2-Fluorocyclopentyl acetate 10 (1.45 gr, $10 \mathrm{mmol}$ ) obtained in the precedent experiment was dissolved in $\mathrm{MTBE}$, phosphate buffer $(0.05 \mathrm{M}, \mathrm{pH}=7.2)$ and Novozyme 435 lipase(0.2 molar equiv.) were added. Then the reaction mixture was stirred at room temperature for 14 hours. The course of reaction was monitored by NMR. When the reaction was completed the lipase was filtered off. 
The organic phase was separated from water phase. The water phase was extracted with MTBE. The organic extracts were dried over sodium sulfate and evaporated. Optical purity was determined by Mosher acid derivatization (98\% ee). Yield 45\%. $[\alpha]_{D}{ }^{20}=+18\left(\mathrm{C}=1, \mathrm{CHCl}_{3}\right) .{ }^{1} \mathrm{H} \mathrm{NMR}\left(\delta, \mathrm{ppm}(\mathrm{J}, \mathrm{Hz}), \mathrm{CDC}_{3}\right): \delta_{\mathrm{H}} 1.3-2.00(\mathrm{~m}, 6$ $\mathrm{H}, \mathrm{CH}_{2}$ ); 2.0-2.1 (br.m, $1 \mathrm{H}, \mathrm{OH}$ ); 4.30 (d, J 14, $1 \mathrm{H}, \mathrm{C} \underline{\mathrm{HOH}}$ ); 4.90 (ddt, J 52.0, J 8.5 and J 3.0, $1 \mathrm{H}, \mathrm{CHF}$ ); ${ }^{13} \mathrm{C} \mathrm{NMR}(\delta$, $\left.\operatorname{ppm}(J, \mathrm{~Hz}), \mathrm{CDCl}_{3}\right): \delta$ c: 19.7; 27.0 (d, J 21.54); 31.2, 57.0 (d, J 27.2. ); 96.0 (d, J 177). ${ }^{19} \mathrm{~F} \mathrm{NMR}\left(\mathrm{CDCl}_{3}\right) ; \delta_{\mathrm{F}}-181.95$ ppm. Found, \%: C 57.30; H 8.75. $\mathrm{C}_{5} \mathrm{H}_{9}$ FO. Calculated, \%: C 57.68; H 8.71.

$m / z: 104.1\left(\mathrm{M}^{+}\right)$

(+)-(1S,2S)- 2-Fluorocyclopentane-1-ol, (3). The racemic trans-2-fluorocyclopentane-1-ol (1.45 g, $10 \mathrm{mmol}$.) (+/)-6 was dissolved in MTBE and the vinyl acetate ( 3 molar equiv.) as acylating agent and Burkholderia cepacia lipase ( 0.1 molar equiv.) as biocatalyst were added. The reaction mixture was stirred at room temperature for 12-14 hours. The reaction was monitored by NMR. When the reaction was completed, the lipase was filtered off and the solvent was evaporated. The residue (mixture of the alcohol and acetate) was separated by column chromatography. In the second fraction was found $(1 S, 2 S)$-fluorocyclopentane-1-ol (1S,2S)-3. Yield $45 \%$. The product was crystallized in pentane at low temperature. Yield $40 \%$, m.p. $21^{\circ} \mathrm{C} .[\alpha]_{\mathrm{D}}{ }^{20}=+25\left(\mathrm{CHCl}_{3}\right) ; \mathrm{Lit}[\alpha]^{22} \mathrm{D}=$ $+10.3\left(\mathrm{CHCl}_{3}, \mathrm{C}=1.1\right){ }^{2}$ Optical purity of the product was established by Mosher acid derivatization and confirmed by HPLC with chiral column $98 \%$ ee). Spectral data were in agreement with literature values. ${ }^{2,11}$

(-)-(1R,2R)-2-Fluorocyclopentane-1-ol, (4). (1R,2R)-2-Fluorocyclopentyl acetate 9 (10 mmol) obtained in the precedent experiment was dissolved in MTBE. Then phosphate buffer $(0.05 \mathrm{M}, \mathrm{pH}=7.2)$ and Novozyme $\left.435^{*}\right)$ ( 0.2 molar equiv.) was added and the reaction mixture was stirred at room temperature. The course of the reaction was monitored by NMR. When the reaction was completed, the lipase was filtered off. The organic phase was separated from water phase. The water phase was extracted 2 times with MTBE. The combined organic extracts were dried over sodium sulfate and evaporated. Optical purity ( $98 \%$ ee) was determined by Mosher acid derivatization. Yield $45 \% .[\alpha]_{D}^{20}=-20\left(\mathrm{C}=1, \mathrm{CHCl}_{3}\right)$.

${ }^{1} \mathrm{H}$ NMR $\left(\delta, \operatorname{ppm}(\mathrm{J}, \mathrm{Hz}), \mathrm{CDC1}_{3}\right): \delta_{\mathrm{H}}$ 1.3-2.00 (m, $\left.6 \mathrm{H}, \mathrm{CH}_{2}\right) ; 2.0-2.1$ (br.m, $\left.1 \mathrm{H}, \mathrm{OH}\right) ; 4.30(\mathrm{~d}, J 12,1 \mathrm{H}$,

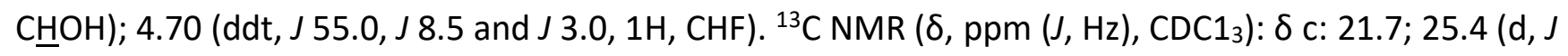
21.54); 31.0; 50.4 (d, J 27.2); 95.0 (d, J 177). ${ }^{19} \mathrm{~F}$ NMR, $\delta_{F}-181.9$ ppm. Found, \%: C 57.32; H 8.72. $\mathrm{C}_{5} \mathrm{H}_{9} \mathrm{FO}$. Calculated, \%: C 57.68; $\mathrm{H}$ 8.71. $\mathrm{m} / \mathrm{z}: 104.1\left(\mathrm{M}^{+}\right)$.

${ }^{*}$ The same yield and ee of 4 were obtained in the reaction with BCL instead of the Novozyme $435^{*}$ )

(1R,2S)-2-Fluorocyclopentyl) isoindoline -1,3-dione, (11)

$(1 S, 2 S)$-Fluorocyclopentan-1-ol $4(2.1 \mathrm{~g}, 20 \mathrm{mmol})$ was dissolved in $10 \mathrm{~mL}$ of absolute THF. Triphenylphosphine $(0.024 \mathrm{~mol})$ and phthalimide $(0.02 \mathrm{~mol})$ were added to the solution. Then, the DEAD was added to the reaction mixture while cooling with an ice-water bath and the mixture was stirred overnight at room temperature. When the reaction was completed. the solvent was evaporated and the residue was purified by column chromatography. Yield 70\%. ${ }^{1} \mathrm{H}$ NMR $\left(\delta, \mathrm{ppm}(\mathrm{J}, \mathrm{Hz}), \mathrm{CDC}_{3}\right): \delta \delta_{\mathrm{H}} 1.75 \mathrm{~m}\left(2 \mathrm{H}, \mathrm{CH}_{2}\right) ; 1.90 \mathrm{~m}\left(2 \mathrm{H}, \mathrm{CH}_{2} \mathrm{CH}_{2}\right) ; 2.6-2.8$ $\mathrm{m}\left(2 \mathrm{H}, \mathrm{CH}_{2}\right) ; 4.5 \mathrm{~d}(1 \mathrm{H}, J$ 5, $\underline{\mathrm{CHOH}}) ; 5.2\left(\mathrm{~d}, J_{\mathrm{HF}} 50 \mathrm{~Hz}, 1 \mathrm{H}, \mathrm{CHF}\right) ; 7.83 ; 7.91\left(\mathrm{C}_{6} \mathrm{H}_{4}\right)$.

\section{(+)-(1R,2S)- 2-fluorocyclopentan-1-aminium chloride, (12).}

$(1 R, 2 S)$-2-Fluorocyclopentyl isoindolyl-1.3-dione 11 (2.3 g, $10 \mathrm{mmol})$ was dissolved in $6 \mathrm{~N}$ hydrochloric acid and refluxed for 5 hours. When the reaction was completed, the precipitate (phthalic acid) was filtered off and the solvent was evaporated. Pure $(1 R, 2 S)$-fluorocyclopentylphenamine hydrochloride was found in the residue. The optical purity of the product was determined by Mosher's acid derivatization. Yield $90 \%, 96 \%$ ee. $[\alpha]_{D}{ }^{20}=+10.81$ (C=0.1, Ethanol).

${ }^{1} \mathrm{H}$ NMR $\left(\delta, \mathrm{ppm},(\mathrm{J}, \mathrm{Hz}), \mathrm{DMSO}-d_{6}\right): \delta_{\mathrm{H}} 1.6 \mathrm{~m}\left(2 \mathrm{H}, \mathrm{CH}_{2}\right) ; 1.90 \mathrm{~m}\left(2 \mathrm{H}, \mathrm{CH}_{2}\right) ; 2.0 \mathrm{~m}\left(2 \mathrm{H}, \mathrm{CH}_{2}\right) ; 3.45 \mathrm{~m}\left(J_{\mathrm{HF}} 26,1 \mathrm{H}\right.$, $\mathrm{CHNH}_{2}$ ) $) ; 5.1 \mathrm{~d}\left(\mathrm{JHF}_{\mathrm{HF}} 55, \mathrm{CHF}\right) ; 8.75 \mathrm{c}\left(3 \mathrm{H}, \mathrm{NH}_{3}{ }^{+}\right) ;{ }^{13} \mathrm{C} \mathrm{NMR}\left(\delta, \mathrm{ppm},(\mathrm{J}, \mathrm{Hz}), \mathrm{CDCl}_{3}\right): \delta \mathrm{c}: 19.90 \mathrm{c}, 28.00 \mathrm{c}, 30.50 \mathrm{c}$, $31.10 \mathrm{c}, 77.0 \mathrm{~d}, J$ 28; 98.0, d (J 180, C-F). ${ }^{19} \mathrm{~F}$ NMR, $\delta_{\mathrm{F}}-190 \mathrm{ppm}$. 
MS-HRMS, $m / z:$ : 104.4 100\%); 105.4 (10) (M+1).

Found, \%: C 43.45; $\mathrm{H}$ 8.21. $\mathrm{C}_{5} \mathrm{H}_{11} \mathrm{ClFN}$. Calculated, \%: C 43.02; $\mathrm{H} 7.94$.

(-)-(1S,2R)-2-Fluorocyclopentan-1-aminium chloride (14). To a solution of $(1 R, 2 R)$-fluorocyclopentanol-1 (1.05 $\mathrm{g}, 10 \mathrm{mmol}$.) in dry THF, triphenylphosphine (1.2 molar equiv.), phthalimide (1,47 $\mathrm{g}, 10 \mathrm{mmol}$.) and DEAD were added while cooling in an ice-water bath. Then the reaction mixture was stirred overnight at room temperature. When the reaction was completed the solvent was evaporated and the residue was purified by column chromatography. $(1 R, 2 S)$-2-Fluorocyclopentyl) isoindolyl-1,3-dione 13 was obtained in $70 \%$ yield. The product was dissolved in $6 \mathrm{~N}$ hydrochloric acid and refluxed for 5 hours. After the completion of the reaction, the precipitate of phthalic acid was filtered off. The mother liquor was evaporated. The residue contained the $(1 S, 2 R)$-2-fluorocyclopentane-1-aminium chloride. The optical purity was monitored by HPLC with a chiral column and by derivatization with Mosher's acid. ${ }^{27}$ Yield 90\%, ee $=96 \%$. $[\alpha]_{\mathrm{D}}{ }^{20}=-9.98$ ( $\mathrm{C}=0.1$, Ethanol).

${ }^{1} \mathrm{H}$ NMR (DMSO-d $\left.d_{6}\right), \delta$, ppm $(\mathrm{J}, \mathrm{Hz}): \delta 1.6 \mathrm{~m}\left(2 \mathrm{H}, \mathrm{CH}_{2}\right) ; 1.85 \mathrm{~m}\left(2 \mathrm{H}, \mathrm{CH}_{2}\right) ; 2.0 \mathrm{~m}\left(2 \mathrm{H}, \mathrm{CH}_{2}\right) ; 3.5 \mathrm{~d}\left(\mathrm{JHF}_{\mathrm{HF}} 26,1 \mathrm{H}, \mathrm{CHNH}_{2}\right)$; $5.15 \mathrm{~d}\left(\mathrm{~J}_{\mathrm{HF}} 55, \mathrm{CHF}\right) ; 8.55 \mathrm{~s}\left(3 \mathrm{H}, \mathrm{NH}_{3}{ }^{+}\right) .{ }^{19} \mathrm{~F} \mathrm{NMR}, \delta \mathrm{F}-190 \mathrm{ppm}$.

MS-HRMS, $m / z$ : 104.4 (100\%); 105.4 (10) (M+1).

Found, \%: C 43.42; H 8.20. $\mathrm{C}_{5} \mathrm{H}_{11} \mathrm{CIFN}$. Calculated, \%: C 43.02; H 7.94.

\section{Supplementary Material}

Copies of ${ }^{1} \mathrm{H},{ }^{19} \mathrm{~F}$ and ${ }^{13} \mathrm{C}$ NMR spectra, mass spectra and HPLC, as well as the determination of optical purity by Mosher's acid derivatization, are provided in the Supplementary Material associated with this paper.

\section{References}

1. Begue, J.-P.; Bonnet-Delpon, D. in Bioorganic and medicinal chemistry of fluorine, John Wiley \& Sons, Hoboken, New Jersey. 2008, 384p.

2. Kalow, J. A.; Doyle, A. G. J. Am. Chem. Soc. 2011, 133, 16001-16012 https://doi.org/10.1021/ja207256s

3. Haufe, G.; Wolker, D.; Frohlich, R. J. Chem. Soc., Perkin Trans. 2 1996, 973-977. https://doi.org/10.1039/P29960000973

4. Fukazawa, T.; Shimoji, Y.; Hashimoto, T. Tetrahedron: Asymmetry 1996, 7, 1649-1658; https://doi.org/10.1016/0957-4166(96)00199-1

5. Enantiocontrolled Synthesis of Fluoro-organic Compounds. Stereochemical Challenges and Biomedicinal Targets; Soloshonok, V. A., Ed.; John Wiley \& Sons: Chichester 1999, pp 307-348

6. Honig, H.; Seufer-Wasserthal, P. Synthesis 1990, 1137-1140. https://doi.org/10.1055/S-1990-27115

7. Bruns, S.; Haufe, G. J. Fluor. Chem. 2000, 104, 247-254. https://doi.org/10.1016/S0022-1139(00)00249-9

8. Szori, K.; Szöllosi, G.; Bartók, M. J. Catalysis 2006, 244, 255-259 http://dx.doi.org/10.1016/j.jcat.2006.09.006

9. Haufe, G.; Bruns, S.; Runge, M. J. Fluor. Chem. 2001, 112, 55-61. https://doi.org/10.1016/S0022-1139(01)00486-9

10. Sattler, A. Haufe, G. Tetrahedron: Asymmetry 1995, 6, 2841-2848. 
https://doi.org/10.1016/0957-4166(95)00375-Y

11. Kalow, J. A.; Doyle, A. G. J. Am. Chem. Soc. 2010, 132, 3268-3269.

https://doi.org/10.1021/ja100161d

12. Kolodiazhna, O. O.; Kolodiazhna, A. O.; Kolodiazhnyi. O. I. Tetrahedron: Asymmetry 2013, 24, 37-42. https://doi.org/10.1016/j.tetasy.2012.11.011

13. Mesecar, A. D.; Koshland, D. E., jr.. Nature 2000, 403, 6770, 614-615.

https://doi.org/10.1038/35001144

14. Cohen, S.; Schultz, R. Proc. Natl. Acad. Sci. USA 1967, 57, 243-249.

https://doi.org/10.1073/pnas.57.2.243

15. Cohen, S.; Schultz, R. J. Biol. Chem. 1968, 243, 2607-2617

https://doi.org/10.1016/S0021-9258(18)93416-2

16. Kobayashi, K.; Uchiyama, M.; Ito, H.; Takahashi, H.; Yoshizumi, T. Bioorg. Med. Chem. Lett. 2009, 19,36273631

https://doi.org/10.1016/j.bmcl.2009.04.116

17. Box; B. P.; Judkins, C. D.; Pennell, A. M. K. US 6,407,076 B1, 2002. Official Gazette of the United States Patent and Trademark Office, 2002, 1259 (3), 3318 -3318

18. Kazlauskas, R. J.; Weissfloch, A. N. E.; Rappaport, A. T.; Cuccia, L. A. J. Org. Chem. 1991, 56, 2656 -2665. https://doi.org/10.1021/acs.biomac.0c01605

19. Gotor-Fernandez, V.; Brieva, R.; Gotor, V. J. Mol. Cat. B. 2006, 40, 111-120.

https://doi.org/10.1016/j.molcatb.2006.02.010

20. Ebert, C.; Felluga, F.; Forzato, C.; Foscato, M.; J. Mol. Catal., B: Enzymatic 2016, 83, 38-45. https://doi.org/10.1016/i.molcatb.2012.06.017

21. Industrial Enzymes: Structure, Function and Applications. Ed. J. Polaina, A. P. MacCabe. Springer Publ., The Netherland,2007, 653p.

22. Ara, M.; Bom, T.; Botton, V.; Altheia, F. M.; Thomas. J. C. Biochem. Eng. J. 2021, 165, 107817-107827. https://doi.org/10.1016/i.bej.2020.107817

23. Basso, E. A.; Abiko, L. A.; Gauze, G. F.; Pontes, R. M. J. Org. Chem. 2011, 76, 145-153 https://doi.org/10.1021/jo101819u

24. Shellhamer, D. F.; Briggs, A. A.; Miller, B. M.; Prince, J. M.; Scott, D. H.; Healsley, V. L. J. Chem. Soc., Perkin Trans. 2 1996, 973-977.

https://doi.org/10.1039/P29960000973

25. Aranda, G.; Jullien, J.; Martin, J. A. Bull. Soc. Chim. Fr. 1966, 9, 2850-2857.

26. Baklouti, A.; El Gharbi, R. J. Fluor. Chem. 1979, 13, 297-314.

https://doi.org/10.1016/S0022-1139(00)82080-1

27. Hoye, T.R.; Jeffrey , C. S.; Shao, F. Nature Protocols 2007, 2, 2451-2458.

https://doi.org/10.1038/nprot.2007.354 